\title{
Halos and Mock Suns
}

ON Tuesday, July 20, about 5. 5 p.m., I saw from this neighbourhood a most remarkable series of halos and parhelia, the general appearance of which is represented in the accompanying figure. (The parhelia at $120^{\circ}, \mathrm{p}^{\mathrm{iii}}$ and $\mathrm{p}^{\mathrm{iv}}$, cannot be represented in the figure.)

As I happened to have a theodolite near at hand, I measured the altitudes and azimuths of the parhelia and contact arches, and also of two points on the larger halo, with the following result :-

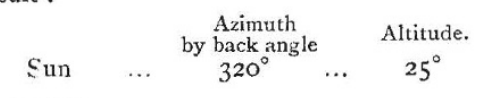

Parhelia

$\begin{array}{llrl}\mathrm{p}^{\mathrm{i}} & \ldots & 347 & \ldots \\ \mathrm{P}^{\mathrm{ii}} & \ldots & 293 & \ldots \\ \mathrm{p}^{\mathrm{iii}} & \ldots & 80 & \ldots \\ \mathrm{p}^{\mathrm{iv}} & \ldots & 200 & \ldots\end{array}$

Contact-arch

to inner halo

Left extremity $\left(A^{i i}\right) \quad \ldots \quad 288_{5}^{\circ} \quad \ldots \quad 39$

Right extremity $\left(A^{i}\right) \quad \ldots \quad 353 \quad \ldots \quad 39$

The positions of the two parhelia $\mathrm{I}^{\mathrm{iii}} \mathrm{P}^{\mathrm{iv}}$ (or more properly speaking, anthelia) at $120^{\circ}$ on either side of the sun, exactly accord with what is given in the text-books, but the solar longitude of the parhelia on the primary halo $27^{\circ}$, and the dimensions of the larger halo $63 \frac{1}{2}^{\circ}$, usually given as $46^{\circ}$, are greater than those usually recorded.

The following features were observed:-

(I) The parhelion, $\mathrm{P}^{\mathrm{ii}} 27^{\circ}$, to the left of the sun, was very brightly visible before that on the right appeared at all.

(2) The parhelic circle appeared to encircle the entire sky, and to be everywhere of the same altitude $-25^{\circ}$-as that of the sun.

(3) The contact arch, $\mathrm{B}$, at the top of the larger halo, was remarkably brilliant, being red on the side adjacent to the sun,

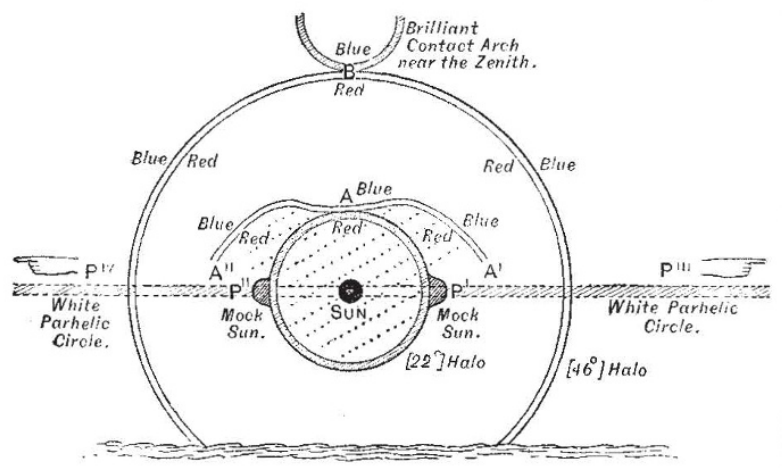

and blue on that furthest from it, and appeared to be almost exactly at the zenith, thus supporting the somewhat rough measurements of the outer halo, which made it considerably larger than the traditional $46^{\circ} .1$

(4) The contact arches $\mathrm{A}^{\mathrm{i}} \mathrm{A}^{\mathrm{ii}}$ were also very brilliant, and the space within them as well as that within the inner halo $h h$ was much darker than that outside.

(5) The colours of the outer halo, $\mathrm{H} \mathrm{H}$, were similar to those of the inner halo, $h h$, viz. red inside and blue outside, but fainter.

(6) The parhelia attached to the inner circle $\mathrm{P}^{\mathrm{i}} \mathrm{p}^{\mathrm{ii}}$ were similarly red inside and blue outside, while those at $120^{\circ}$ were perfectly white.

The whole phenomenon lasted about twenty minutes, and was one of the most beautiful sights I ever saw. I was experimenting with a captive balloon at the time, or should have been able to make more detailed observations. I hear that on Monday night a deluge of rain of a tropical character fell at Dieppe. The cloud which caused these unusual optical phenomena appeared to be of the type termed by Poëy globo-cirrus. I shall be

$x$ Sun's altitude $=25^{\circ}$, radius of halo $=63^{\frac{1}{3}}$, which would make the lower extremity of the top contact-arch $88 \frac{1}{2}^{\circ}$ above horizon. glad to hear if any corroborative measurements were made by other observers.

Tunbridge Wells, July

P.S. No parhelia were visible at the junction of the larger halo $\mathrm{H} \mathrm{H}$ with the parhelic circle. Also there were no signs of the rare $90^{\circ}$ radius halo. The radius of the inner halo was not measured, but as the lateral deviation of the parhelia $p^{i}$ pii $^{\mathrm{ii}}$ from the points in which it intersected the parhelic circle for a solar altitude of $25^{\circ}$ should be about $2^{\circ} 7^{\prime}$, this would make the radius of the inner halo $24^{\circ} 53^{\prime}$ instead of $22^{\circ} 30^{\prime}$ as is generally the case.

ON Tuesday afternoon, 2oth inst, while sketching near Cranbrook, in the Weald of Kent, I saw a masnificent example of mock suns and solar rainbow circles.

Fr, $m$ an early part of the day the sky had been, I think, more splendid in its cloud arrangements of $\operatorname{cirr} *$ cumulus than I have ever seen in this or any other country, though I have always been a delighted student of these phenomena. From Io a. m. to about $4 \mathrm{p} . \mathrm{m}$. there was an incessant change of loveliness in the forms and positions of the clouds and the remarkable perspectives thereby produced, to the intense admiration of myself and wife. But about 4 o'clock one half of the heavens from the horizon to the zenith became nearly covered with a thin stratum of dark clouds, which resembled more than anythi g else innumerable long bundles of cotton fibre, placed in every possible direction. The other half of the shy was of the richest and most delicate ultramarine as a background, and the fleecy mare's tail and flocks of sheep cloudlets as the subjects. On the dark strata of clouds the mock suns made their appearance, the real sun shining through the clouds with great intensity.

The whole phenomenon did not fade out till nearly 6 o'clock. As I saw it for some time reflected in a large sheet of water, I had good opportunities of studying it.

The setting of the sun that night was the most gorgeous pageant-myriads of golden streauers, in groups, being sent up from purple and scarlet clouds.

Jasper Road, Upper Norwood, July 28

N.B. The c'ouds in the vicinity of the sun were slightly opalescent. - R. H. F. R.

\section{A Singular $\mathrm{C}=\mathrm{se}$}

O.N March 2 last a small fishing-boat engaged in trawling a about 20 kilometres from the coast, off Monte Argentaro (Tuscan Maremma), captured a specimen of the Mediterranean Red Mullet (Mullus barbatus) tightly incased in a large colony of Pyrosoma atlanticum. The head of the fish had reached the bottom of the social cylinder, which fitted it to a nicety. The Pyrosoma measures 0.112 millimetre in length and 0.032 millimetre at its greatest transverse diameter; the mullet is 0.152 millimetre long, so that only 0.040 milli netre of its tail projects beyond the tightly fitting Pyrosoma! The fish was taken alive, but how it could have lived in such conditions or how it got into its tight jacket is to me most enigmatical. Even admitting a certain amount of elasticity in the tight-fitting tube in which its head, body, and fins are incased, its movements could only have been very limited, and a very inc mplete respiration and perhaps nutrition might have $\mathrm{c}$ sme to it through the orifices of the zooids.

Young fish, especially Scomberoids, are often found under the shelter of Medusæ and Physalia-the case of Fierasfer getting in'o the visceral cavity of Holothuria is well known; but it is the fir:t time I have seen or heard of so singular a case of impriconment as the one related above, and I therefore thought it worthy of the attention of the readers of NATURE. The specimen is preserved in alcohol in the rich ichthyological series of the collectio I of Italian Vertebrata in the Florence Royal Zo Jlogical Museum.

Florence, July 29

Henry H. Giglioli

\section{The Weather at Caracas}

THE following notes on the weather at Caracas during the remarkable storm from May II to 15 may not be void of interest :-

We had a rather low barometer on May 8 (Io a m., 682.93 mm. ; 4 p.m., 68I $99 \mathrm{~mm}$.), but then it rose gradually till May $18\left(685^{\circ} 4^{2}\right.$ and $683^{\circ} \cdot 17 \mathrm{~mm}$. respectively). There had been no rain in the first twelve days of the month, but from 